\title{
Sweet and sour: the impact of differential glycosylation in cancer cells undergoing epithelial-mesenchymal transition
}

\section{Leonardo Freire-de-Lima*}

Laboratório de Glicobiologia, Instituto de Biofísica Carlos Chagas Filho, Universidade Federal do Rio de Janeiro, Rio de Janeiro, RJ, Brazil

\section{Edited by:}

Roger Chammas, Universidade de São Paulo, Brazil

\section{Reviewed by:}

Christian Stock, University of

Muenster, Germany

Shoukat Dedhar, University of British

Columbia, Canada

${ }^{*}$ Correspondence:

Leonardo Freire-de-Lima, Laboratório de Glicobiologia, Instituto de Biofísica Carlos Chagas Filho, Universidade Federal do Rio de Janeiro, Av. Carlos Chagas Filho 373, Centro de Ciências da Saúde-Bloco C-42, Cidade

Universitária, Rio de Janeiro, RJ 21941-902, Brazil

e-mail: leolima@biof.ufrj.br
Glycosylation changes are a feature of disease states. One clear example is cancer cells, which commonly express glycans at atypical levels or with different structural attributes than those found in normal cells. Epithelial-mesenchymal transition (EMT) was initially recognized as an important step for morphogenesis during embryonic development, and is now shown to be one of the key steps promoting tumor metastasis. Cancer cells undergoing EMT are characterized by significant changes in glycosylation of the extracellular matrix (ECM) components and cell-surface glycoconjugates. Current scientific methodology enables all hallmarks of EMT to be monitored in vitro and this experimental model has been extensively used in oncology research during the last 10 years. Several studies have shown that cell-surface carbohydrates attached to proteins through the amino acids, serine, or threonine (O-glycans), are involved in tumor progression and metastasis, however, the impact of $O$-glycans on EMT is poorly understood. Recent studies have demonstrated that transforming growth factor-beta (TGF- $\beta$ ), a known EMT inducer, has the ability to promote the up-regulation of a site-specific O-glycosylation in the IIICS domain of human oncofetal fibronectin, a major ECM component expressed by cancer cells and embryonic tissues. Armed with the knowledge that cell-surface glycoconjugates play a major role in the maintenance of cell homeostasis and that EMT is closely associated with glycosylation changes, we may benefit from understanding how unusual glycans can govern the molecular pathways associated with cancer progression. This review initially focuses on some well-known changes found in O-glycans expressed by cancer cells, and then discusses how these alterations may modulate the EMT process.

Keywords: epithelial-mesenchymal transition, extracellular matrix, cancer, metastasis, glycosylation, oncofetal fibronectin, glycosyltransferases

\section{THE APPLICATION OF GLYCOBIOLOGY IN CANCER RESEARCH}

Cancer is a complex progressive disease that involves a series of genetic-environmental interactions, which cannot occur without the dysfunction of multiple systems, including DNA repair, apoptosis, and immune function. Epigenetic mechanisms responding to numerous internal and external cues in a dynamic ongoing exchange play a key role in mediating environmental influences on gene expression and tumor development. The cancer causing agents (carcinogens) can be present in the air, chemicals, food, water, and even the sunlight people are exposed to. Since epithelial cells line the respiratory and alimentary tracts, cover the skin, and metabolize carcinogens, it is not surprising that over $90 \%$ of cancers arise from epithelia (1). The sequencing of the human genome holds benefits for many fields, from molecular medicine to human evolution. The Human Genome Project (HGP) has helped in the understanding of human diseases, including the identification of oncogenes and mutations linked to different forms of cancer (2). However, one major lesson from HGP is that the absolute number of genes encoded by the human genome is not the best parameter for defining its biological complexity. Instead, the complex functions associated with human health and disease are determined by combinatorial expansion of genomic information in the form of post-translational modifications (PTMs).
The quantitative and qualitative control of a vast number of proteins in eukaryotes is maintained by PTMs, such as phosphorylation, ubiquitination, methylation, hydroxylation, proteolysis, $\mathrm{N}$-acetylation, and glycosylation $(3,4)$. These intricate events require a multitude of specific enzymes that are tissue- and species-specific. The subsequent changes modulate the folding, physicochemical properties, conformation, stability, distribution, immunogenicity, and activity of the proteins (4-6). There is an increasing awareness of post-genome glycosylation as a potentially important form of post-translational protein modification. Glycosylated proteins have long been known to participate in a plethora of biological processes. These include signal transduction, inflammation, viral entry, bacteria-host interactions, cell-cell interactions, and morphogenesis, as well as the development and progression of chronic diseases, such as cancer (7-9). It is wellaccepted that in cancer cells, the expression and/or activity of glycosyltransferases is altered, yielding an "aberrant" glycophenotype when compared to their normal counterparts $(9,10)$. These changes result in structural variations of glycans on glycoproteins and glycolipids, altering their interaction with carbohydratebinding proteins and modulating the role of the membrane glycan in cell adhesion and signal transduction required for cell motility $(11,12)$. Furthermore, the aberrant glycosylation of proteins 
in cancer cells offers an interesting diagnostic perspective in distinguishing what is benign and what is malign $(13,14)$. Several glycoproteins carrying atypical glycophenotypes have been used as cancer glycobiomarkers (15). Examples include the carcinoembryonic antigen (16), the prostate-specific antigen (17), and the CA-125 antigen (18), used as markers for colorectal, prostate, and ovarian cancers, respectively. The transformation of glycobiology from a descriptive and phenomenological discipline, to one where the regulatory principles are understood and predictably manipulated has opened up new opportunities in the study of cancer and the search for effective therapeutic modalities.

\section{O-LINKED GLYCAN STRUCTURES AND THEIR CHANGES IN CANCER CELLS}

Glycosylation is a main class of PTMs. There are two basic types of protein glycosylation: $\mathrm{N}$-glycosylation and O-glycosylation. These have significant differences in terms of their biosynthesis and structure, as well as their location within the protein chain (7). In $N$-linked glycans, the nitrogen atom in the side chain of asparagine is attached to $N$-acetylglucosamine (GlcNAc). The sequence can be Asn-X-Ser or Asn-X-Thr, where X is any kind of amino acid except proline (19). In O-linked glycans, the oxygen atom in the side chain of serine or threonine is attached to $N$-acetylgalactosamine (GalNAc) (20). Furthermore, the glycopeptides Asn-GlcNAc or Ser/Thr-GalNAc may be extended by numerous and specific glycosyltransferases (7).

It is well understood that both $N$ - and $O$-linked glycans mediate essential processes in development (21), host-pathogen interactions (22-24), immune cell recognition (25), and cancer development and progression $(9,26)$. In the case of cancer, alterations in both glycan types frequently modulate the invasive potential of tumor cells and their interactions with stromal partners, including fibroblasts, leukocytes, platelets, and endothelial cells (27). This discussion focuses on the significance of O-glycan changes in cancer evolution. However, there are many interesting reviews addressing how atypical $N$-glycans may govern the cancer development and progression [see reviews in Ref. $(28,29)]$.

In $O$-linked glycans, the oligosaccharides display considerable structural and antigenic diversity. The GalNAc $\alpha$-Ser/Thr linkage has been considered a hallmark of mucins, where it occurs in clusters (30). This linkage has also been found in a wide variety of other proteins, such as extracellular matrix (ECM) components (31). The path of O-glycosylation is a key factor in the biological activity of glycoproteins involved with the control of cell differentiation and with the regulation of cell growth through apoptosis and proliferation (32). The addition of GalNAc to Ser or Thr is mediated by glycosyltransferases, known as $N$ acetylgalactosaminyltransferases (GalNAc-Ts) (33). Furthermore, the glycopeptide GalNAc $\alpha$-Ser/Thr may be extended with additional sugars, including galactose (Gal), GlcNAc, fucose (Fuc), or sialic acid (Sia). There is no glycan extension in cancer cells carrying mutations in the COSMC gene, which encodes for core-1 $\beta 3$-Gal-T-specific molecular chaperone. Here, the glycopeptide GalNAc $\alpha$-Ser/Thr, referred to as Tn-antigen, may be sialylated by the action of specific $\alpha 2-6$ sialyltransferases ( $\alpha 2-6$ STs), creating the tumor-associated antigen known as sialyl Tn-antigen (34). In general, there are four common $\mathrm{O}$-glycan core structures in mammalian tissues (core- $1 \Rightarrow$ core- 4 ) that depend on the arrangement of the added sugars (Figure 1).

The biosynthesis of core- 1 and core- 2 structures is entirely dependent on core-1-synthase, a galactosyltransferase (Gal-T), which converts the initial glycopeptide (GalNAc $\alpha 1-S e r / T h r)$ to Gal $\beta 1$-3GalNAc $\alpha 1-S e r / T h r$ (core-1 or T-antigen). Core- 1 is then converted to core-2 by $\beta 1-6 N$-acetylglucosaminyltransferase $(\mathrm{C} 2 \mathrm{GnT})$. There are three enzymes that can synthesize core2: C2GnT-1, -2, and -3. Core-2 O-glycan is a scaffold for the subsequent production of lactosamine repeats (poly- $N$ acetyllactosamine) on $\mathrm{O}$-glycans. Poly- $\mathrm{N}$-acetyllactosamine formation is a crucial step for the terminal modification by Sia and Fuc (31). The carbohydrates that contain Sia or Fuc perform important roles in the various steps of tumor formation and tumor progression $(35,36)$. Enhanced expression of certain Sia types or their linkages is often correlated with the poor prognosis for many human malignancies. Core-3 O-glycan is synthesized onto the initial core- 1 by core- 3 synthase ( $\beta 3 \mathrm{GnT}-6)$, which adds $\beta 1-3$-linked GlcNAc to GalNAc at the reducing terminus. Core- $4 \mathrm{O}$-glycan is then synthesized by the addition of $\beta 1-6$ GlcNAc to the core- 3 acceptor by C2GnT-2 (Figure 1).

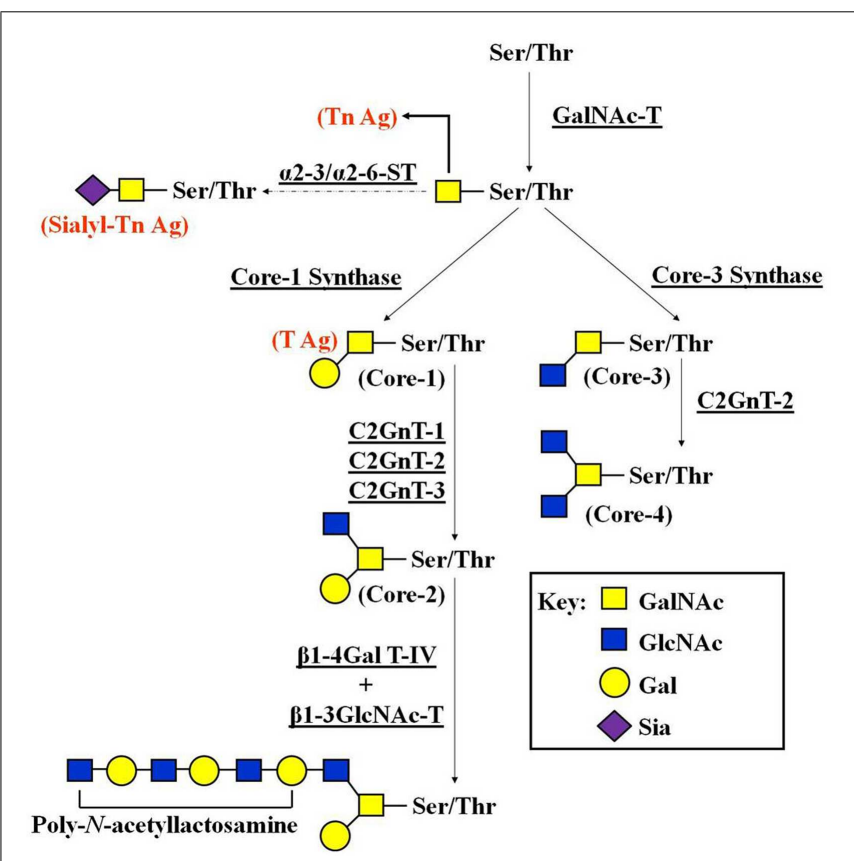

FIGURE 1 | Pathways of $\boldsymbol{O}$-glycan biosynthesis. To begin synthesis of core-2 and core-4 O-glycans, GalNAc is transferred to a serine or threonine residue in a polypeptide by the GalNAc-T. GalNAc-Ser/Thr is then converted by core-1 synthase to Gal $\beta 1-3 \mathrm{GalNAc-Ser} / \mathrm{Thr}$ (core-1). Core-1 is converted to core-2 by $\mathrm{C} 2 \mathrm{GnT}-1,-2$, and -3 . $\beta$-1,4-galactosyltransferase IV ( $\beta 1-4 \mathrm{Gal}-\mathrm{T}$ IV), together with $\beta-1,3-N$-acetylglucosaminyltransferase $V$ ( $\beta 1-3 \mathrm{GICNAc-T}$ V), synthesizes poly- $N$-acetyllactosamine on core-2 O-glycans. The number of Galß1-4GIcNAc disaccharide unit repeats varies depending on the carrier molecules and cell types. GalNAc-Ser/Thr is also converted by $\beta 3 \mathrm{GnT}-6$ to core-3. Core-3 is then converted by C2GnT-2 to core-4. As discussed in the main text, the accumulation of truncated versions of expressed oligosaccharides (T-, Tn-, and sialyl Tn-antigens) occurs due to impaired activity of glycosyltransferases involved in the elongation of $O$-linked glycan. 
Out of the many known types of biosynthetic reactions in $O$-linked glycosylation pathways, only a few structural changes have been frequently connected with tumor development and progression (9, 11, 37-42). Most are either truncated versions of normally expressed oligosaccharides (T-, Tn-, and sialyl Tnantigens) (Figure 1) or relatively unusual types of outer/terminal oligosaccharide sequences, such as Lewis structures. Such structures arise from the up-regulation of some glycosyltransferases, the down-regulation of competing glycosyltransferases, or the changes in the elongation of the core oligosaccharide structures that create favored acceptors for the capping glycosyltransferases $(9,43)$. It is well-documented that these truncated antigens show increased expression in tumor cells, which make them potential cancer biomarkers (41), and candidates for the development of vaccines with anti-tumor properties (44). However, little is known about their participation in cancer progression, since few papers have addressed the biological impact of these structures in activating molecular pathways related to cancer cell invasion and metastasis.

It is well described that mucins provide protection on epithelial surfaces, and exert control on cell signaling. Nevertheless, mucins in cancer cells carrying aberrant $O$-glycophenotypes induce profound tumor-promoting effects, partly mediated through interactions with their glycan moieties (45). MUC1 is greatly glycosylated in benign cells of the breast, prostate, ovary, and pancreas, and is minimally expressed and limited to the apical side of the glands. Transformation of these cells into malignant cells is associated with the over-expression of MUC1, and dysregulation of $O$-glycans of MUC1 (46). Previous studies showed that the binding of galectin3 to MUC1 bearing the oncofetal Thomsen-Friedenreich antigen $[\mathrm{Gal} \beta 1,3$ GalNAc- $\alpha$ (TF)] increases the cancer cell adhesion to the endothelium (47). In addition, recent reports demonstrated that the VNTR sequence found in the extracellular domain of MUC1 may carry altered O-glycophenotypes, which could be responsible to modulate cancer cell invasion and migration (48). Recently, Wang and colleagues (49) described the strong procarcinogenic potential of the $N$-acetylgalactosaminyltransferase3 (GalNAc-T3) in advanced epithelial ovarian cancer (EOC). The authors demonstrated that the knockdown of GalNAc-T3, a possible GalNAc-T involved in oncofetal fibronectin (onfFN) biosynthesis (50), promoted an increase of the cell adhesion molecules $\beta$-catenin and E-cadherin. These are normally suppressed by MUC1 in aggressive cancer cells, thus supporting the role of the GalNAc-T3/MUC1 axis in EOC invasion (49). Although several papers have connected the altered expression of MUC1 to epithelial-mesenchymal transition (EMT) (51-54), the impact of atypical $\mathrm{O}$-glycans carried by MUC1 on cancer cells undergoing EMT is still unknown.

Another example is the sialomucin CD43, which is one of the most prevalent $O$-glycosylated mucins expressed by leukocytes. It was found to be expressed by human adenomas and carcinomas, but not in normal epithelial cells (55). In addition, $\mathrm{Fu}$ and colleagues (56) recently demonstrated that human lung carcinoma cells became more sensitive to TNF- $\alpha$-induced cell death after CD43 knockdown. However, the impact of CD43 on EMT is unrecognized. So far, the roles of $O$-linked glycans in promoting tumor metastasis have been investigated by focusing on selectin-mediated interactions between tumor cells and other cells types (57-60). Sialyl Lewis antigens, which may be found in core-2 $\mathrm{O}$-glycans, bind to selectins expressed on endothelial cells, favoring the extravasation of cancer cells into metastasis target organs $(61,62)$. Recently $(63,64)$, intracellular glycoproteins modified by a single $O$-linked-beta- $N$-acetylglucosamine (O-GlcNAc) have shown to modulate cell-cell adhesion and cell motility. The involvement of these $O$-GlcNAcylated glycoproteins on EMT process has been described (65).

Since altered glycoconjugates expressed by cancer cells are typically detected during fetal development, they are known as oncofetal antigens. These proteins are often measurable in the blood and may be used for cancer diagnosis and to monitor the effectiveness of cancer treatment. Examples include $\alpha$-fetoprotein, which is produced by hepatocellular carcinoma and some germ cell tumors (66), the carcinoembryonic antigen, which is elevated in people with colon cancer (67), and O-glycosylated onfFN, which was discovered in 1985 by Matsuura and Hakomori (68).

\section{O-GLYCOSYLATED ONCOFETAL FIBRONECTIN: A MAJOR ECM COMPONENT EXPRESSED BY CANCER CELLS AND EMBRYONIC TISSUES}

Since the same cell behaviors and processes that are indispensable for embryonic development are also essential for cancer progression (69), it is not surprising that in the last two decades, we have seen that cancer biology and development biology "walk hand in hand" $(70,71)$. The notion that the local microenvironment plays an essential role in regulating cell behavior, a central theme in classical embryology, has become increasingly accepted in the cancer biology field (72-74). Previous studies have been dedicated to determining how cellular components of the niche initiate and promote cancer development (75). However, more recent progress has also highlighted the importance of non-cellular components of the niche, especially the ECM during cancer progression (76-79). The ECM is a mixture of many different molecular components that vary between organisms, tissues within one organism, and sometimes with the developmental age. It is not a static structure, but is instead being constantly remodeled by the cells within it and around it, by the opposing influences of ECM synthesis and destruction by proteolytic enzymes. The ECM is composed of three main classes of macromolecules: structural proteins (collagen and elastin), specialized proteins (fibrillin, laminin, and FN), and glycosaminoglycans. Amongst all of the ECM components in vertebrates, $\mathrm{FN}$ has received considerable attention for its role in cell-matrix interactions. This adhesive glycoprotein is critically important in vertebrate development, since gene disruption studies demonstrated early embryonic lethality in mice without the FN gene. Although FN has been studied for more than two decades, this remarkably complex molecule is still the subject of exciting discoveries. FN usually exists as a dimer, composed of two nearly identical $\sim 250 \mathrm{kDa}$ subunits linked covalently together near their C-termini by a pair of disulfide bonds. FN binds different ECM components and mediates homotypic interactions (Figure 2A). Until the mid-80s, two major types of FN were known: the plasma $(\mathrm{pFN})$ and cellular FN (cFN), which was found in the pericellular matrix or secreted in the culture medium of fibroblasts. In 1985, Matsuura and Hakomori developed a monoclonal antibody $(\mathrm{mAb})$ termed FDC-6, which was initially reactive with 

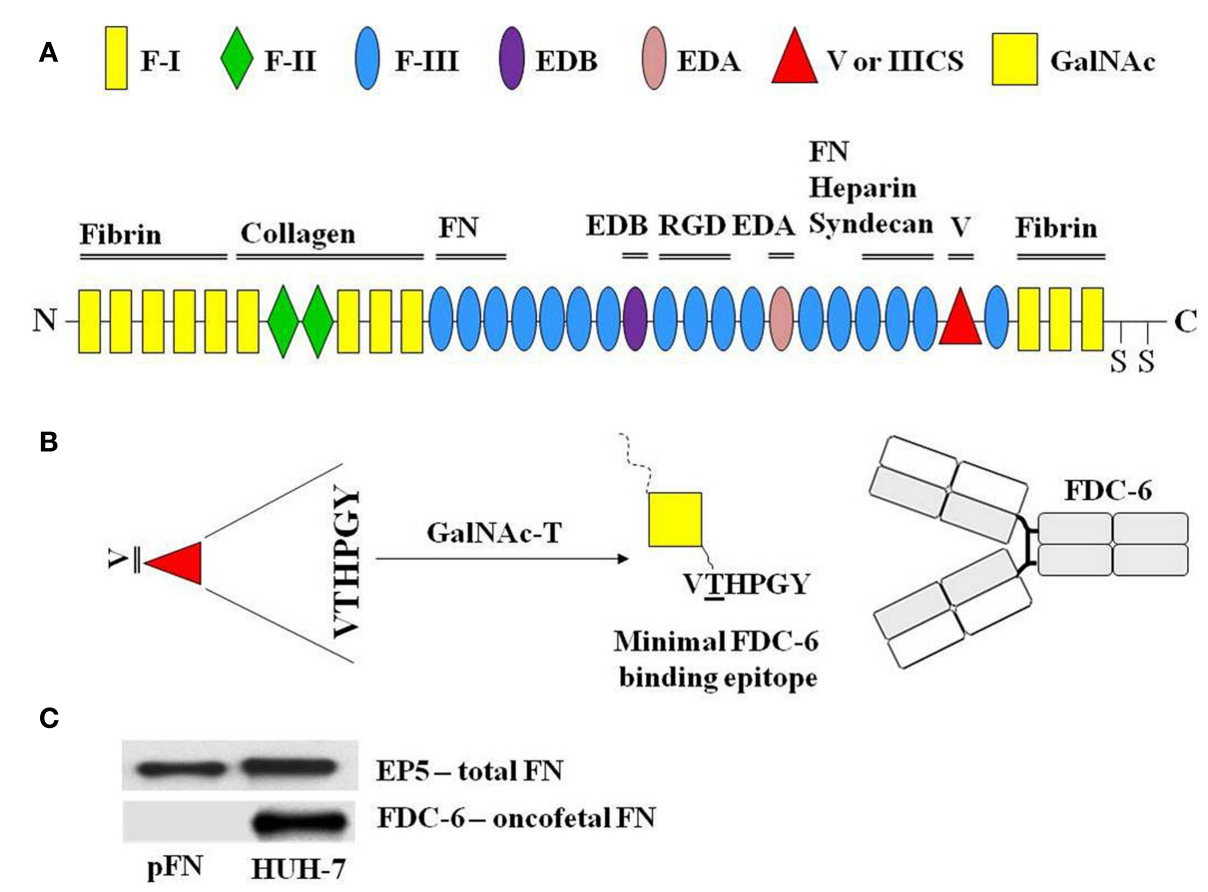

FIGURE 2 |The modular structure of fibronectin and its binding domains FN consists of type I, type II, and type III repeats. Sets of repeats constitute binding domains for fibrin, FN, syndecan, collagen, and heparin, as indicated. $\mathrm{SS}$ indicates the $\mathrm{C}$-terminal cysteines that form the dimer. The EDB and EDA domains that are produced by alternative splicing are indicated (A). Between type I and type III repeats there is another alternatively spliced segment, which is termed IIICS or variable region. During the alternative splicing, five different IIICS variants may be generated (V0, V64, V89, V95, and V120). Excluding V0, all others variants may hold the hexapeptide (VTHPGY) required to create the $O$-glycosylated onfFN, which is produced from the addition of a GalNAc unit at the Thr residue of the hexapeptide (VTHPGY) by a specific GalNAc-T. It creates the oncofetal epitope required for FDC-6 binding (B). As described, FDC-6 reacts exclusively with the $O$-glycosylated onfFN, but not with non-O-glycosylated FN or plasma FN (pFN) (C).
cFN expressed by fibroblasts, but not with pFN. Furthermore, the authors demonstrated that FNs isolated from normal adult tissues were not reactive with FDC-6, whereas FNs isolated from established cell lines, such as fetal and cancer tissues carried an extra structure, which favored FDC- 6 binding. This FN became known as onfFN. Proteolytic digestion of glycoproteins showed that the structure defined by FDC-6 antibody was present in the variable (V) region or IIICS domain of FN (68). After characterization of the primary structure of $\mathrm{V}$ region, Matsuura and colleagues isolated the specific structure for FDC- 6 binding. The comparison of this structure with other structures that lack reactivity with FDC- 6 showed that the FDC-6 binding epitope was composed of a GalNAc linked to Thr in the hexapeptide VTHPGY. In addition, the authors demonstrated that the reactivity is dependent on the combination of both the sugar moiety and the peptide unit, since neither the sugar nor the peptide moiety alone could form the epitope structure (80). Further studies showed that the FDC-6 non-reactive synthetic peptide containing the VTHPGY sequence can be converted into FDC-6-reactive form. This happens after the incubation with GalNac-T and UDP- $\left[{ }^{3} \mathrm{H}\right] \mathrm{GalNAc}$ in the homogenate of carcinoma cell lines and the human fetal fibroblast cell lines. Such a conversion did not take place when the same enzyme fraction of normal adult tissue was incubated with the VTHPGY peptide under the same conditions. Thus, the occurrence of GalNAc-T recognizing the VTHPGY peptide sequence was shown to be specific for fetal and cancer tissues, and absent in normal adult tissues (81).

It is now known that $\mathrm{FN}$ isoforms are developmentally regulated and generated as a result of alternative splicing of the primary FN transcript (82). The mature FN molecules comprise of a series of repeating amino acid sequences, termed as F-I, FII, and F-III structural modules. Twelve F-I modules make up the amino-terminal and carboxy-terminal region of the molecule, and are involved mainly in fibrin and collagen binding. Only two F-II modules are found in FN. They are instrumental in binding collagen. The most abundant module in FN is FIII, which contains the RGD FN receptor recognition sequence along with binding sites for other integrins and ECM components (Figure 2A) (71). Depending on the tissue type and/or cellular conditions, the FN molecule is made up of 15-17 F-III modules. The $\mathrm{V}$ region, which does not fall into any of these categories, along with extra domain B (EDB) and extra domain A (EDA) (both F-III modules), is regulated through alternative splicing of FN pre-mRNA (71). The V region is located between F-I and FIII modules and can generate five (V0, V64, V89, V95, and V120) different variants after the alternative splicing $(71,72)$. All variants, except V0 may contain the hexapeptide (VTHPGY) that can be $\mathrm{O}$-glycosylated on its Thr residue by a specific GalNAc$\mathrm{T}$, creating the oncofetal epitope required for the FDC-6 binding (Figure 2B). 
As described above, FDC-6 reacts exclusively with $O$ glycosylated onfFN, but not with non-O-glycosylated $\mathrm{FN}$ or plasma FN (pFN) (Figure 2C). onfFN has been identified within several human tumors and developmental tissues (83-85). Furthermore, a few recent reports have demonstrated that both $O$-glycosylated and non- $O$-glycosylated $F N s$ display distinct functionalities in cancer cells undergoing EMT (see section below) (86-88). However, further studies are necessary to clarify their divergent roles in cancer evolution.

Although the development of a cancer cell arises from epigenetic alterations, as well as somatic mutations in essential genes for cell physiology, the selective pressures that take place in the tumor microenvironment are crucial for the emergence of transformed cells with different genotypes and/or glycophenotypes. These events can modulate signaling pathways that exert control on proliferation, motility, and half-life, which create conditions for such cells to acquire invasive properties. For a long time, little was known about the biology of cancer cells with metastatic properties. However, with the advent of experimental models, which allowed the studies of molecular pathways triggered in invasive cancer cells has generated valuable information that can be used for future diagnostic and therapeutic purposes.

\section{THE ROLE OF EMT IN CANCER PROGRESSION AND METASTASIS}

Given the ultimate diversity of tissues in a mature organism, cells can adopt different fates. This process, known as differentiation, provides cells with their distinct identities and specialized functions. Initially, it was thought that differentiation was a one-way process, and those terminally differentiated cells, i.e., cells of the epithelium, were unable to lose their individuality and differentiate toward a cell type of another lineage. However, more recent studies have shown that cells of the epithelium can dedifferentiate toward a mesenchymal state, enabling the cells to migrate, and form new structures at a distant site. This phenomenon termed EMT is a crucial biological event that takes place during embryonic development and wound healing. Next to these physiological events, EMT pathways are also activated during diseases. Cancer cells can go through EMT to detach from the primary tumor, migrate toward the vasculature, get transported by the blood circulation through the body, and settle at a distant site where metastatic foci can be formed (89-92). Nowadays, all hallmarks of EMT can be monitored in vitro, and this unique experimental model has been used to shed light on the molecular, biochemical, and biomechanical cues of invasive cells. In literature, three different subtypes of EMT are recognized. Although EMT, by definition, results in the formation of migratory mesenchymal cells, each subtype represents a specific biological event (93). The earliest EMT (type 1 EMT) is highly regulated and is associated with embryonic implantation and organ formation. Type 2 EMT is associated with inflammation and fibrosis, and is now increasingly recognized in adult pathological conditions. In the context of fibrosis, the inflammation persists and fibroblastic cells accumulate in the tissue, secreting large concentrations of ECM components. The deposition of these ECM components inhibits organ function and can ultimately lead to organ failure and organ destruction (94). Type 3 EMT is associated with cancer progression and occurs in epithelial tumors

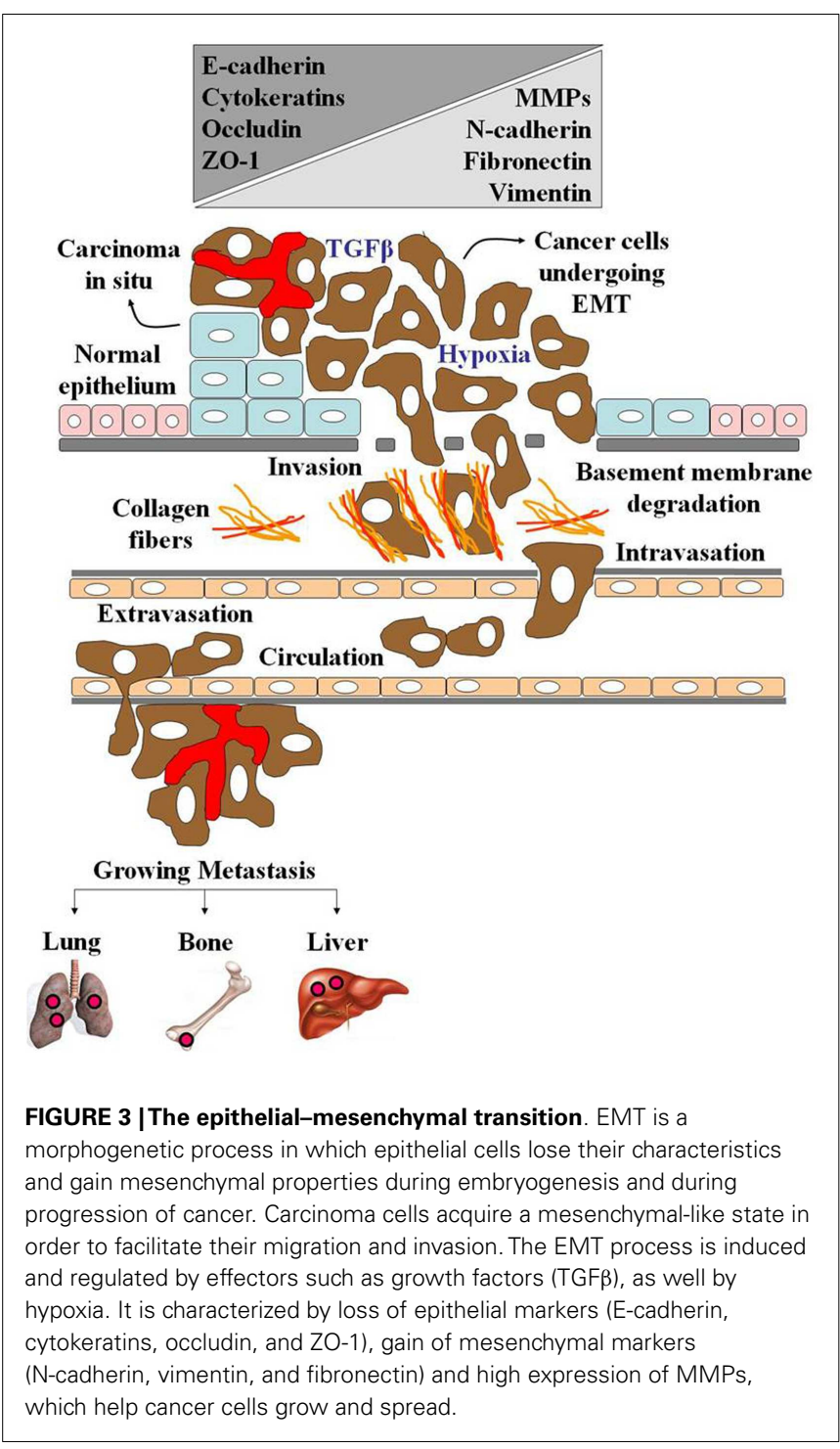

$(95,96)$. Figure 3 illustrates how the type 3 EMT may modulate the cancer cell progression.

In normal epithelial tissues, the cells are shown tightly juxtaposed and form a polarized sheet with differing apical and basal surfaces. When the genes involved in the control of cell growth and cell death undergo epigenetic alterations and somatic mutations, the mutated cells proliferate in an uncontrolled way, and favor the development of carcinoma in situ (Figure 3). Growth factors, such as TGF- $\beta$, and the compromised oxygen demand (hypoxia condition) in the tumor microenvironment activates the molecular pathways related to EMT. During this process, EMT master regulators, such as the transcription factors Twist, Snail, and SIP1, lead to dramatic changes in gene expression profiles and cellular behavior. Twist, Snail, and SIP1 repress E-cadherin expression via E-boxes in its promoter and trigger expression of an entire EMT transcriptional program. The cells show a spindle-like-shape, as well a significant reduction of epithelial markers (E-cadherin, cytokeratins, occludin, and ZO-1), which is accompanied by the emergence of 
mesenchymal markers ( $\mathrm{N}$-cadherin, vimentin, and $\mathrm{FN}$ ). In addition, the transformed cells secrete metalloproteinases (MMPs), which help degrade the basal membrane components and also expresses high levels of mesenchymal integrins, which may facilitate their interaction with ECM components, such as collagen fibers (Figure 3). Finally, the transformed cells are able to reach the bloodstream and colonize distant organs and tissues inducing metastasis (Figure 3). Over 45 years, it is well-accepted that atypical glycosylation may be detected in all types of experimental and human cancers. However, although many tumor-associated antigens have been used as tumor glycobiomarkers, their role on cancer evolution is not well studied. In part, this can be explained by the difficulties in closely following the biochemical and molecular events of tumor development and progression in vivo. Along this line, the EMT process has helped us to unveil the cues of the altered glycosylation in invasive cancer cells.

\section{EMT: THE GLYCAN CONNECTION}

There is universal agreement that most of the early events in the emergence of neoplasia involve genetic alterations, and it seems unlikely that altered glycosylation per se plays a major role at this stage. However, few reports have demonstrated how these atypical glycosylations may govern the molecular pathways related to cancer cell invasion and metastasis. The impact of altered glycans modulating cancer cell behavior is of central significance in recent cancer research. However, little attention has been given to this topic, mainly because the structural and functional concepts of glycosylation in cancer are more complex than those for certain proteins and their genes in defining cancer cell phenotypes. Pioneering papers published by Hakomori's group demonstrated that the EMT process may be used to shed light on the impact of atypical glycans expressed by invasive epithelial cells $(86,87$, 97-99). After the first paper published in 2009, where the participation of specific glycosphingolipids (GSLs) in human and mouse mammary epithelial cells undergoing EMT was demonstrated, a few papers discussing the impact of atypical glycans, as well as the altered expression of glyco-genes have been published (100-103). However, the implication of the unusual $O$-linked glycans on EMT process has not been well explored. So far, the impact of altered $O$ glycans on EMT has been addressed to the $O$-glycosylated onfFN. Although onfFN was discovered almost 30 years ago (68), until very recently, there had been no studies that describe its role in cancer biology. Over the last few years, the O-glycosylated onfFN has only been used for diagnostic purposes (104).

Recent studies brought to light the involvement of onfFN during the EMT process. The first report demonstrated the upregulation of onfFN in human prostate epithelial cells treated with TGF- $\beta$. The authors observed that the treated cells expressed high levels of mRNA for FN carrying the IIICS domain, which contains the VTHPGY sequence (86). Although it is recognized that the incubation of the hexapeptide cited above with the microsomal fraction of cancer cells favored the appearance of the oncofetal epitope, the identity of the GalNAc-T responsible for this phenomenon remained unknown for a long time. Previous biochemical studies revealed that both GalNAc-T3 and/or GalNAcT6 recombinant enzymes were able to glycosylate the VTHPGY sequence, suggesting that one or both glycosyltransferases would participate in onfFN biosynthesis (50). To analyze the relevance of GalNAc-T3 and/or GalNAc-T6 on EMT, Freire-de-Lima and colleagues (86) silenced the expression of both glycosyltransferases and observed that the double knockdown cells failed to undergo TGF- $\beta$-induced EMT. These were the first results that evinced a cell system where both GalNAc-T3 and GalNAc-T6 were involved in onfFN biosynthesis, as well as indirectly demonstrating the importance of $\mathrm{O}$-glycosylated onfFN in human epithelial cells undergoing EMT. To check the main type of FN expressed during the EMT process, a new hybridoma, $\mathrm{YKH} 1$, which produces a $\mathrm{mAb}$ directed against the non-O-glycosylated VTHPGY sequence found in FNs expressed by normal tissues (norFN) has been produced (87). The comparative results revealed that TGF- $\beta$-treated cells expressed a significant amount of onfFN when compared with non-treated cells. On the other hand, there was no observable change on YKH1 binding between the control and TGF- $\beta$ treated cells, suggesting that the majority, if not all of the $\mathrm{FN}$ produced during EMT is onfFN (87). Additionally, both norFN and onfFN were purified by immunoaffinity columns to directly evaluate their relevance on EMT. Interestingly, the authors observed that only the $O$-glycosylated onfFN was able to induce the EMT-related events (87). Although the major ligands for onfFN, as well as the molecular mechanisms triggered by this unusual glycoprotein are still unknown, the results described above have a significant biological impact, suggesting that onfFN may be further used as a possible candidate for the development of vaccines with anti-carcinogenic properties.

Increasing evidence suggests that a metabolic disturbance, such as hyperglycemia, is closely linked to cancer development and progression. Several epidemiological studies have confirmed that diabetic patients are more susceptible to cancer development when compared with healthy individuals (105-108). Furthermore, diabetic patients have a poorer prognosis than those non-diabetic patients with the same types of cancer $(109,110)$. The exact mechanism for the increased cancer risk in patients with diabetes is unknown. Due to a potential correlation between diabetes and cancer, studies evaluating the cancer risk of medications used to treat diabetes are emerging $(111,112)$. However, given the importance of glycoconjugates on cell biology, the possibility that atypical glycans in diabetic individuals may support the tumor development and/or evolution cannot be excluded. The upregulation of glucose transporters (Gluts), which contributes to increased influx of glucose, is one of the metabolic facets adopted by cancer cells. It is believed that $\sim 95 \%$ of glucose is deviated to the glycolytic pathway, and $\sim 3-5 \%$ is skewed to the hexosamine biosynthetic pathway (HBP) that generates the activated monosaccharides UDP-GlcNac and UDP-GalNAc, which are essential for the biosynthesis of $N$ - and $O$-linked glycans respectively. Following this thought process; it would not be surprising if cancer cells maintained in a high glucose condition were able to express more $O$-glycosylated onfFN than those cells kept in a normoglycemic condition.

Over the last few years, several papers evinced that the maintenance of different cell types in high glucose condition promoted the up-regulation of FN expression $(113,114)$. Furthermore, recent works have demonstrated that a high glucose condition contributes to the increased production of TGF- $\beta$ in vitro by diverse 
cell lines (115-117). It is well described that FN is an important mesenchymal marker, and that TGF- $\beta$ is a potently known EMT inducer. However, no studies have shown a direct link between a hyperglycemic condition and the EMT process. Furthermore, it is not known what type of FN would be expressed in a hyperglycemic condition. We recently demonstrated that the maintenance of a human adenocarcinoma cell line (A549) in hyperglycemic, but not in normoglycemic condition, was able to induce the EMT process, which was accompanied by the up-regulation of the mRNA for FN transcripts carrying the IIICS domain and onfFN expression (88). In addition, we have shown that these phenomena seem to be fully dependent of the endogenous TGF- $\beta$ produced in high glucose, since the neutralization of TGF- $\beta$ by anti-TGF- $\beta$ antibodies abrogated the onfFN expression. These results have important implications, since they make a direct link between diabetes, a metabolic disorder which affects millions of people worldwide, and carcinogenesis. It also reinforces the idea that aberrant glycosylation of glycoconjugates in diabetic patients may have a key role in oncogenesis and tumor progression. Further studies are going on in our lab to clarify this hypothesis.

\section{CONCLUSION}

This review has summarized how unusual $O$-glycans may influence cancer cell behavior, focusing on the effects mediated by the $O$-glycosylated onfFN in EMT, a biological phenomenon that has revolutionized the study of carcinogenesis. As commented above, several papers have described altered $O$-glycophenotypes adopted by cancer cells. However, there are few reports regarding how these alterations may govern the molecular pathways related to the cancer evolution. The involvement of atypical glycans in cancer cells undergoing EMT is a topic still not well studied, but the area is very promising, given the relevance of glycoconjugates in the maintenance of cell homeostasis, as well by the fact that EMT precedes cell metastasis. Research efforts over the last few years have concentrated on the impact of an unusual $O$-linked glycan in the FN structure. Future results will be necessary to support previous observations, but it is plausible to speculate that onfFN may be further used as a promising candidate for an anti-cancer vaccine. Basic Local Alignment Search Tool (BLAST) analysis (118) revealed that human kallikrein 12 (h-klk12), a serine protease expressed by adult and fetal tissues (119), share the sameVTHPGY sequence that is $O$ glycosylated in the IIICS domain of human onfFN. It has been well described that h-klk12 modulates many physiological processes $(120,121)$, as well tumor cell invasion and metastasis $(122,123)$. Previous studies have shown that cancer cells express kallikreins with atypical glycophenotypes (124). Knowing this, it is reasonable to speculate that h-klk12 may act as substrate for GalNAc-T3 and/or GalNAc-T6 to create the oncofetal epitope recognized by FDC-6. However, this has never been demonstrated. In addition to FN, other glycoproteins associated with cell adhesion, such as cytokeratins $(125,126)$, plakoglobin $(127,128)$, E-cadherin (129), and beta-catenin $(63,130)$ are known to express their peculiar $O$ glycophenotypes. Although the EMT process is deeply associated with glycosylation changes, there is little information regarding the impact of the atypical $O$-linked glycans adopted by these glycoproteins in cancer cells undergoing EMT. Given the importance of these $\mathrm{O}$-glycophenotypes in the maintenance of epithelial cell polarity, it would be interesting to further explore this topic in cancer biology. Besides reinforcing the idea that oncoglycobiology is an important biological field, one of the major goals of this review is to show that the EMT model may render useful information about the glycosylation changes in invasive and metastatic cancer cells, which may be additionally used for therapeutic and diagnostic purposes.

\section{ACKNOWLEDGMENTS}

The author is grateful to Profs. Lucia Mendonça-Previato and Jose Osvaldo Previato for continued advice, and thanks native speaker, Wai Cheu Lai, for revision of the manuscript. This work was supported by Fundação Carlos Chagas Filho de Amparo à Pesquisa do Estado do Rio de Janeiro (FAPERJ), and Conselho Nacional de Desenvolvimento Cientifico e Tecnológico (CNPq).

\section{REFERENCES}

1. Birchmeier W, Behrens J, Weidner KM, Hulsken J, Birchmeier C. Epithelial differentiation and the control of metastasis in carcinomas. Curr Top Microbiol Immunol (1996) 213(Pt 2):117-35.

2. Alfoldi J, Lindblad-Toh K. Comparative genomics as a tool to understand evolution and disease. Genome Res (2013) 23(7):1063-8. doi:10.1101/gr.157503.113

3. Karve TM, Cheema AK. Small changes huge impact: the role of protein posttranslational modifications in cellular homeostasis and disease. J Amino Acids (2011) 2011:207691. doi:10.4061/2011/207691

4. Seo J, Lee KJ. Post-translational modifications and their biological functions: proteomic analysis and systematic approaches. J Biochem Mol Biol (2004) 37(1):35-44. doi:10.5483/BMBRep.2004.37.1.035

5. Woodsmith J, Kamburov A, Stelzl U. Dual coordination of post translational modifications in human protein networks. PLoS Comput Biol (2013) 9(3):e1002933. doi:10.1371/journal.pcbi.1002933

6. Schuldt A. Post-translational modification: a SUMO protease for stress protection. Nat Rev Mol Cell Biol (2013) 14(5):263. doi:10.1038/nrm3569

7. Spiro RG. Protein glycosylation: nature, distribution, enzymatic formation, and disease implications of glycopeptide bonds. Glycobiology (2002) 12(4):43R-56R. doi:10.1093/glycob/12.4.43R

8. Hakomori S. Aberrant glycosylation in cancer cell membranes as focused on glycolipids: overview and perspectives. Cancer Res (1985) 45:2405-14.

9. Hakomori S. Glycosylation defining cancer malignancy: new wine in an old bottle. Proc Natl Acad Sci U S A (2002) 99(16):10231-3. doi:10.1073/pnas. 172380699

10. Kim YJ, Varki A. Perspectives on the significance of altered glycosylation of glycoproteins in cancer. Glycoconj J (1997) 14(5):569-76. doi:10.1023/A: 1018580324971

11. Ono M, Hakomori S. Glycosylation defining cancer cell motility and invasiveness. Glycoconj J (2004) 20(1):71-8. doi:10.1023/B:GLYC.0000018019. 22070.7d

12. Park S-Y, Yoon S-J, Freire-de-Lima L, Kim J-H, Hakomori S. Control of cell motility by interaction of gangliosides, tetraspanins, and epidermal growth factor receptor in A431 vs. KB epidermoid tumor cells. Carbohydr Res (2009) 344(12):1479-86. doi:10.1016/j.carres.2009.04.032

13. Peracaula R, Barrabes S, Sarrats A, Rudd PM, de Llorens R. Altered glycosylation in tumours focused to cancer diagnosis. Dis Markers (2008) 25(4-5):207-18. doi:10.1155/2008/797629

14. Meany DL, Chan DW. Aberrant glycosylation associated with enzymes as cancer biomarkers. Clin Proteomics (2011) 8(1):7. doi:10.1186/1559-0275-8-7

15. Drake PM, Cho W, Li B, Prakobphol A, Johansen E, Anderson NL, et al. Sweetening the pot: adding glycosylation to the biomarker discovery equation. Clin Chem (2010) 56(2):223-36. doi:10.1373/clinchem.2009.136333

16. Duffy MJ. Carcinoembryonic antigen as a marker for colorectal cancer: is it clinically useful? Clin Chem (2001) 47(4):624-30.

17. Peracaula R, Tabares G, Royle L, Harvey DJ, Dwek RA, Rudd PM, et al. Altered glycosylation pattern allows the distinction between prostate-specific antigen (PSA) from normal and tumor origins. Glycobiology (2003) 13(6):457-70. doi:10.1093/glycob/cwg041 
18. Saldova R, Struwe WB, Wynne K, Elia G, Duffy MJ, Rudd PM. Exploring the glycosylation of serum CA125. Int J Mol Sci (2013) 14(8):15636-54. doi:10.3390/ijms140815636

19. Weerapana E, Imperiali B. Asparagine-linked protein glycosylation: from eukaryotic to prokaryotic systems. Glycobiology (2006) 16(6):91R-101R. doi: 10.1093/glycob/cwj099

20. Kleene R, Schachner M. Glycans and neural cell interactions. Nat Rev Neurosci (2004) 5(3):195-208. doi:10.1038/nrn1349

21. Ohtsubo K, Marth JD. Glycosylation in cellular mechanisms of health and disease. Cell (2006) 126(5):855-67.

22. Freire-de-Lima L, Oliveira IA, Neves JL, Penha LL, Alisson-Silva F, Dias WB, et al. Sialic acid: a sweet swing between mammalian host and Trypanosoma cruzi. Front Immunol (2012) 3:356. doi:10.3389/fimmu.2012.00356

23. Szymanski CM, Wren BW. Protein glycosylation in bacterial mucosal pathogens. Nat Rev Microbiol (2005) 3(3):225-37. doi:10.1038/nrmicrol100

24. Freire-de-Lima L, Alisson-Silva F, Carvalho ST, Takiya CM, Rodrigues MM, DosReis GA, et al. Trypanosoma cruzi subverts host cell sialylation and may compromise antigen-specific CD8+ T cell responses. J Biol Chem (2010) 285(18):13388-96. doi:10.1074/jbc.M109.096305

25. Marth JD, Grewal PK. Mammalian glycosylation in immunity. Nat Rev Immunol (2008) 8(11):874-87. doi:10.1038/nri2417

26. Dube DH, Bertozzi CR. Glycans in cancer and inflammation - potential for therapeutics and diagnostics. Nat Rev Drug Discov (2005) 4(6):477-88. doi:10.1038/nrd1751

27. Mueller MM, Fusenig NE. Friends or foes - bipolar effects of the tumour stroma in cancer. Nat Rev Cancer (2004) 4(11):839-49. doi:10.1038/nrc1477

28. Lau KS, Dennis JW. N-glycans in cancer progression. Glycobiology (2008) 18(10):750-60. doi:10.1093/glycob/cwn071

29. Taniguchi N, Korekane H. Branched N-glycans and their implications for cell adhesion, signaling and clinical applications for cancer biomarkers and in therapeutics. BMB Rep (2011) 44(12):772-81. doi:10.5483/BMBRep.2011. 44.12.772

30. Tian E, Ten Hagen KG. Recent insights into the biological roles of mucintype O-glycosylation. Glycoconj J (2009) 26(3):325-34. doi:10.1007/s10719008-9162-4

31. Tsuboi S, Hatakeyama S, Ohyama C, Fukuda M. Two opposing roles of Oglycans in tumor metastasis. Trends Mol Med (2012) 18(4):224-32. doi:10. 1016/j.molmed.2012.02.001

32. Patsos G, Andre S, Roeckel N, Gromes R, Gebert J, Kopitz J, et al. Compensation of loss of protein function in microsatellite-unstable colon cancer cells (HCT116): a gene-dependent effect on the cell surface glycan profile. Glycobiology (2009) 19(7):726-34. doi:10.1093/glycob/cwp040

33. Gill DJ, Clausen H, Bard F. Location, location, location: new insights into OGalNAc protein glycosylation. Trends Cell Biol (2011) 21(3):149-58. doi:10. 1016/j.tcb.2010.11.004

34. Ju T, Wang Y, Aryal RP, Lehoux SD, Ding X, Kudelka MR, et al. Tn and sialylTn antigens, aberrant O-glycomics as human disease markers. Proteomics Clin Appl (2013) 7(9-10):618-31. doi:10.1002/prca.201300024

35. Fernandez-Rodriguez J, Feijoo-Carnero C, Merino-Trigo A, Paez de la Cadena M, Rodriguez-Berrocal FJ, de Carlos A, et al. Immunohistochemical analysis of sialic acid and fucose composition in human colorectal adenocarcinoma. Tumour Biol (2000) 21(3):153-64. doi:10.1159/000030122

36. Bathi RJ, Nandimath K, Kannan N, Shetty P. Evaluation of glycoproteins as prognosticators in head and neck malignancy. Indian J Dent Res (2001) 12(2):93-9.

37. Dennis JW, Laferte S. Tumor cell surface carbohydrate and the metastatic phenotype. Cancer Metastasis Rev (1987) 5(3):185-204. doi:10.1007/BF00046998

38. Handa K, Hakomori SI. Carbohydrate to carbohydrate interaction in development process and cancer progression. Glycoconj J (2012) 29(8-9):627-37. doi:10.1007/s10719-012-9380-7

39. Baldus SE, Engelmann K, Hanisch FG. MUC1 and the MUCs: a family of human mucins with impact in cancer biology. Crit Rev Clin Lab Sci (2004) 41(2):189-231. doi:10.1080/10408360490452040

40. Pinho S, Marcos NT, Ferreira B, Carvalho AS, Oliveira MJ, Santos-Silva F, et al. Biological significance of cancer-associated sialyl-Tn antigen: modulation of malignant phenotype in gastric carcinoma cells. Cancer Lett (2007) 249(2):157-70. doi:10.1016/j.canlet.2006.08.010
41. Pinto R, Carvalho AS, Conze T, Magalhaes A, Picco G, Burchell JM, et al. Identification of new cancer biomarkers based on aberrant mucin glycoforms by in situ proximity ligation. J Cell Mol Med (2012) 16(7):1474-84. doi:10.1111/j.1582-4934.2011.01436.x

42. Mazal D, Lo-Man R, Bay S, Pritsch O, Deriaud E, Ganneau C, et al. Monoclonal antibodies toward different Tn-amino acid backbones display distinct recognition patterns on human cancer cells. Implications for effective immunotargeting of cancer. Cancer Immunol Immunother (2013) 62(6):1107-22. doi:10.1007/s00262-013-1425-7

43. Kudo T, Ikehara Y, Togayachi A, Morozumi K, Watanabe M, Nakamura M, et al. Up-regulation of a set of glycosyltransferase genes in human colorectal cancer. Lab Invest (1998) 78(7):797-811.

44. Tarp MA, Clausen H. Mucin-type O-glycosylation and its potential use in drug and vaccine development. Biochim Biophys Acta (2008) 1780(3):546-63. doi:10.1016/j.bbagen.2007.09.010

45. Wu YM, Nowack DD, Omenn GS, Haab BB. Mucin glycosylation is altered by pro-inflammatory signaling in pancreatic-cancer cells. J Proteome Res (2009) 8(4):1876-86. doi:10.1021/pr8008379

46. Deguchi T, Tanemura M, Miyoshi E, Nagano H, Machida T, Ohmura Y, et al. Increased immunogenicity of tumor-associated antigen, mucin 1, engineered to express alpha-gal epitopes: a novel approach to immunotherapy in pancreatic cancer. Cancer Res (2010) 70(13):5259-69. doi:10.1158/0008-5472.CAN09-4313

47. Yu LG, Andrews N, Zhao Q, McKean D, Williams JF, Connor LJ, et al. Galectin3 interaction with Thomsen-Friedenreich disaccharide on cancer-associated MUC1 causes increased cancer cell endothelial adhesion. J Biol Chem (2007) 282(1):773-81. doi:10.1074/jbc.M606862200

48. Cascio S, Farkas AM, Hughey RP, Finn OJ. Altered glycosylation of MUC1 influences its association with CIN85: the role of this novel complex in cancer cell invasion and migration. Oncotarget (2013) 4(10):1686-97.

49. Wang ZQ, Bachvarova M, Morin C, Plante M, Gregoire J, Renaud MC, et al. Role of the polypeptide $\mathrm{N}$-acetylgalactosaminyltransferase 3 in ovarian cancer progression: possible implications in abnormal mucin O-glycosylation. Oncotarget (2014) 5(2):544-60.

50. Bennett EP, Hassan H, Mandel U, Hollingsworth MA, Akisawa N, Ikematsu $\mathrm{Y}$, et al. Cloning and characterization of a close homologue of human UDP-N-acetyl-alpha-D-galactosamine:polypeptide Nacetylgalactosaminyltransferase-T3, designated GalNAc-T6. Evidence for genetic but not functional redundancy. J Biol Chem (1999) 274(36):25362-70. doi:10.1074/jbc.274.36.25362

51. Gnemmi V, Bouillez A, Gaudelot K, Hemon B, Ringot B, Pottier N, et al. MUC1 drives epithelial-mesenchymal transition in renal carcinoma through Wnt/beta-catenin pathway and interaction with SNAIL promoter. Cancer Lett (2013). doi:10.1016/j.canlet.2013.12.029

52. Ponnusamy MP, Seshacharyulu P, Lakshmanan I, Vaz AP, Chugh S, Batra SK. Emerging role of mucins in epithelial to mesenchymal transition. Curr Cancer Drug Targets (2013) 13(9):945-56. doi:10.2174/15680096113136660100

53. Rajabi H,Alam M, Takahashi H, Kharbanda A, Guha M, Ahmad R, et al. MUC1$\mathrm{C}$ oncoprotein activates the ZEB1/miR-200c regulatory loop and epithelialmesenchymal transition. Oncogene (2013). doi:10.1038/onc.2013.114

54. Roy LD, Sahraei M, Subramani DB, Besmer D, Nath S, Tinder TL, et al. MUC1 enhances invasiveness of pancreatic cancer cells by inducing epithelial to mesenchymal transition. Oncogene (2011) 30(12):1449-59. doi:10.1038/ onc. 2010.526

55. Sikut R, Nilsson O, Baeckstrom D, Hansson GC. Colon adenoma and cancer cells aberrantly express the leukocyte-associated sialoglycoprotein CD43. Biochem Biophys Res Commun (1997) 238(2):612-6. doi:10.1006/bbrc. 1997.7334

56. Fu Q, Cash SE, Andersen JJ, Kennedy CR, Oldenburg DG, Zander VB, et al. CD43 in the nucleus and cytoplasm of lung cancer is a potential therapeutic target. Int J Cancer (2013) 132(8):1761-70. doi:10.1002/ijc.27873

57. Bendas G, Borsig L. Cancer cell adhesion and metastasis: selectins, integrins, and the inhibitory potential of heparins. Int J Cell Biol (2012) 2012:676731. doi:10.1155/2012/676731

58. Gil-Bernabe AM, Lucotti S, Muschel RJ. Coagulation and metastasis: what does the experimental literature tell us? Br J Haematol (2013) 162(4):433-41. doi:10.1111/bjh.12381 
59. Wirtz D, Konstantopoulos K, Searson PC. The physics of cancer: the role of physical interactions and mechanical forces in metastasis. Nat Rev Cancer (2011) 11(7):512-22. doi:10.1038/nrc3080

60. Konstantopoulos K, Thomas SN. Cancer cells in transit: the vascular interactions of tumor cells. Annu Rev Biomed Eng (2009) 11:177-202. doi:10.1146/ annurev-bioeng-061008-124949

61. Ugorski M, Laskowska A. Sialyl Lewis(a): a tumor-associated carbohydrate antigen involved in adhesion and metastatic potential of cancer cells. Acta Biochim Pol (2002) 49(2):303-11.

62. Sozzani P, Arisio R, Porpiglia M, Benedetto C. Is Sialyl Lewis x antigen expression a prognostic factor in patients with breast cancer? Int J Surg Pathol (2008) 16(4):365-74. doi:10.1177/1066896908324668

63. Sayat R, Leber B, Grubac V, Wiltshire L, Persad S. O-GlcNAc-glycosylation of beta-catenin regulates its nuclear localization and transcriptional activity. Exp Cell Res (2008) 314(15):2774-87. doi:10.1016/j.yexcr.2008.05.017

64. Jin FZ, Yu C, Zhao DZ, Wu MJ, Yang Z. A correlation between altered O-GlcNAcylation, migration and with changes in E-cadherin levels in ovarian cancer cells. Exp Cell Res (2013) 319(10):1482-90. doi:10.1016/j.yexcr.2013. 03.013

65. Park SY, Kim HS, Kim NH, Ji S, Cha SY, Kang JG, et al. Snaill is stabilized by O-GlcNAc modification in hyperglycaemic condition. EMBO J (2010) 29(22):3787-96. doi:10.1038/emboj.2010.254

66. Bei R, Mizejewski GJ. Alpha fetoprotein is more than a hepatocellular cancer biomarker: from spontaneous immune response in cancer patients to the development of an AFP-based cancer vaccine. Curr Mol Med (2011) 11(7):564-81. doi:10.2174/156652411800615162

67. Amri R, Bordeianou LG, Sylla P, Berger DL. Preoperative carcinoembryonic antigen as an outcome predictor in colon cancer. J Surg Oncol (2013) 108(1):14-8. doi:10.1002/jso.23352

68. Matsuura H, Hakomori S. The oncofetal domain of fibronectin defined by monoclonal antibody FDC-6: its presence in fibronectins from fetal and tumor tissues and its absence in those from normal adult tissues and plasma. Proc Natl Acad Sci U S A (1985) 82(19):6517-21. doi:10.1073/pnas.82.19.6517

69. Egeblad M, Nakasone ES, Werb Z. Tumors as organs: complex tissues that interface with the entire organism. Dev Cell (2010) 18(6):884-901. doi:10.1016/j. devcel.2010.05.012

70. Xie K, Abbruzzese JL. Developmental biology informs cancer: the emerging role of the hedgehog signaling pathway in upper gastrointestinal cancers. Cancer Cell (2003) 4(4):245-7. doi:10.1016/S1535-6108(03)00246-0

71. Radtke F, Clevers H. Self-renewal and cancer of the gut: two sides of a coin. Science (2005) 307(5717):1904-9. doi:10.1126/science.1104815

72. Bissell MJ, Radisky D. Putting tumours in context. Nat Rev Cancer (2001) 1(1):46-54. doi:10.1038/35094059

73. Wiseman BS, Werb Z. Stromal effects on mammary gland development and breast cancer. Science (2002) 296(5570):1046-9. doi:10.1126/science.1067431

74. Bissell MJ, Labarge MA. Context, tissue plasticity, and cancer: are tumor stem cells also regulated by the microenvironment? Cancer Cell (2005) 7(1):17-23. doi:10.1016/j.ccr.2004.12.013

75. Bhowmick NA, Neilson EG, Moses HL. Stromal fibroblasts in cancer initiation and progression. Nature (2004) 432(7015):332-7. doi:10.1038/nature03096

76. Sternlicht MD, Lochter A, Sympson CJ, Huey B, Rougier JP, Gray JW, et al. The stromal proteinase MMP3/stromelysin-1 promotes mammary carcinogenesis. Cell (1999) 98(2):137-46.

77. Paszek MJ, Zahir N, Johnson KR, Lakins JN, Rozenberg GI, Gefen A, et al. Tensional homeostasis and the malignant phenotype. Cancer Cell (2005) 8(3):241-54. doi:10.1016/j.ccr.2005.08.010

78. Erler JT, Weaver VM. Three-dimensional context regulation of metastasis. Clin Exp Metastasis (2009) 26(1):35-49. doi:10.1007/s10585-008-9209-8

79. Levental KR, Yu H, Kass L, Lakins JN, Egeblad M, Erler JT, et al. Matrix crosslinking forces tumor progression by enhancing integrin signaling. Cell (2009) 139(5):891-906. doi:10.1016/j.cell.2009.10.027

80. Matsuura H, Takio K, Titani K, Greene T, Levery SB, Salyan MEK, et al. The oncofetal structure of human fibronectin defined by monoclonal antibody FDC-6: unique structural requirement for the antigenic specificity provided by a glycosylhexapeptide. J Biol Chem (1988) 263(7):3314-22.

81. Matsuura H, Greene T, Hakomori S. An alpha-N-acetylgalactosaminylation at the threonine residue of a defined peptide sequence creates the oncofetal peptide epitope in human fibronectin. J Biol Chem (1989) 264(18):10472-6.
82. White ES, Muro AF. Fibronectin splice variants: understanding their multiple roles in health and disease using engineered mouse models. IUBMB Life (2011) 63(7):538-46. doi:10.1002/iub.493

83. Inufusa $H$, Nakamura $M$, Adachi $T$, Nakatani $Y$, Shindo K, Yasutomi $M$, et al. Localization of oncofetal and normal fibronectin in colorectal cancer. Correlation with histologic grade, liver metastasis, and prognosis. Cancer (1995) 75(12):2802-8. doi:10.1002/1097-0142(19950615)75:12<2802::AIDCNCR2820751204>3.0.CO;2-O

84. Loridon-Rosa B, Vielh P, Matsuura H, Clausen H, Cuadrado C, Burtin P. Distribution of oncofetal fibronectin in human mammary tumors: immunofluorescence study on histological sections. Cancer Res (1990) 50:1608-12.

85. Mandel U, Gaggero B, Reibel J, Therkildsen MH, Dabelsteen E, Clausen H. Oncofetal fibronectins in oral carcinomas: correlation of two different types. APMIS (1994) 102(9):695-702. doi:10.1111/j.1699-0463.1994.tb05222.x

86. Freire-de-Lima L, Gelfenbeyn K, Ding Y, Mandel U, Clausen H, Handa $\mathrm{K}$, et al. Involvement of $\mathrm{O}$-glycosylation defining oncofetal fibronectin in epithelial-mesenchymal transition process. Proc Natl Acad Sci U S A (2011) 108(43):17690-5. doi:10.1073/pnas.1115191108

87. Ding Y, Gelfenbeyn K, Freire-de-Lima L, Handa K, Hakomori SI. Induction of epithelial-mesenchymal transition with O-glycosylated oncofetal fibronectin. FEBS Lett (2012) 586(13):1813-20. doi:10.1016/j.febslet.2012.05.020

88. Alisson-Silva F, Freire-de-Lima L, Donadio JL, Lucena MC, Penha L, Sa-Diniz $\mathrm{JN}$, et al. Increase of O-glycosylated oncofetal fibronectin in high glucoseinduced epithelial-mesenchymal transition of cultured human epithelial cells. PLoS One (2013) 8(4):e60471. doi:10.1371/journal.pone.0060471

89. Tsai JH, Yang J. Epithelial-mesenchymal plasticity in carcinoma metastasis. Genes Dev (2013) 27(20):2192-206. doi:10.1101/gad.225334.113

90. Karamitopoulou E. Role of epithelial-mesenchymal transition in pancreatic ductal adenocarcinoma: is tumor budding the missing link? Front Oncol (2013) 3:221. doi:10.3389/fonc.2013.00221

91. Catalano V, Turdo A, Di Franco S, Dieli F, Todaro M, Stassi G. Tumor and its microenvironment: a synergistic interplay. Semin Cancer Biol (2013) 23(6 Pt B):522-32. doi:10.1016/j.semcancer.2013.08.007

92. Creighton CJ, Gibbons DL, Kurie JM. The role of epithelial-mesenchymal transition programming in invasion and metastasis: a clinical perspective. Cancer Manag Res (2013) 5:187-95. doi:10.2147/CMAR.S35171

93. Zeisberg M, Neilson EG. Biomarkers for epithelial-mesenchymal transitions. J Clin Invest (2009) 119(6):1429-37. doi:10.1172/JCI36183

94. Thiery JP, Acloque H, Huang RJY, Nieto MA. Epithelial-mesenchymal transitions in development and disease. Cell (2009) 139(5):871-90. doi:10.1016/j. cell.2009.11.007

95. Kalluri R, Weinberg RA. The basics of epithelial-mesenchymal transition. JClin Invest (2009) 119(6):1420-8. doi:10.1172/JCI39104

96. Klymkowsky MW, Savagner P. Epithelial-mesenchymal transition: a cancer researcher's conceptual friend and foe. Am J Pathol (2009) 174(5):1588-93. doi:10.2353/ajpath.2009.080545

97. Guan F, Handa K, Hakomori S. Specific glycosphingolipids mediate epithelialto-mesenchymal transition of human and mouse epithelial cell lines. Proc Natl Acad Sci U S A (2009) 106(18):7461-6. doi:10.1073/pnas.0902368106

98. Guan F, Schaffer L, Handa K, Hakomori S. Functional role of gangliotetraosylceramide in epithelial-to-mesenchymal transition process induced by hypoxia and by TGF-beta. FASEB J (2010) 24(12):4889-903. doi:10.1096/fj.10-162107

99. Liang YJ, Ding Y, Levery SB, Lobaton M, Handa K, Hakomori SI. Differential expression profiles of glycosphingolipids in human breast cancer stem cells vs. cancer non-stem cells. Proc Natl Acad Sci U S A (2013) 110(13):4968-73. doi:10.1073/pnas. 1302825110

100. Maupin KA, Sinha A, Eugster E, Miller J, Ross J, Paulino V, et al. Glycogene expression alterations associated with pancreatic cancer epithelialmesenchymal transition in complementary model systems. PLoS One (2010) 5(9):e13002. doi:10.1371/journal.pone.0013002

101. Pinho SS, Oliveira P, Cabral J, Carvalho S, Huntsman D, Gartner F, et al. Loss and recovery of Mgat3 and GnT-III mediated E-cadherin N-glycosylation is a mechanism involved in epithelial-mesenchymal-epithelial transitions. PLoS One (2012) 7(3):e33191. doi:10.1371/journal.pone.0033191

102. Lin H, Wang D, Wu T, Dong C, Shen N, Sun Y, et al. Blocking core fucosylation of TGF-betal receptors downregulates their functions and attenuates the epithelial-mesenchymal transition of renal tubular cells. Am J Physiol Renal Physiol (2011) 300(4):F1017-25. doi:10.1152/ajprenal.00426.2010 
103. Xu Q, Isaji T, Lu Y, Gu W, Kondo M, Fukuda T, et al. Roles of $\mathrm{N}$-acetylglucosaminyltransferase III in epithelial-to-mesenchymal transition induced by transforming growth factor betal (TGF-betal) in epithelial cell lines. J Biol Chem (2012) 287(20):16563-74. doi:10.1074/jbc.M111.262154

104. Richter P, Junker K, Franz M, Berndt A, Geyer C, Gajda M, et al. IIICS de novo glycosylated fibronectin as a marker for invasiveness in urothelial carcinoma of the urinary bladder (UBC). J Cancer Res Clin Oncol (2008) 134(10):1059-65. doi:10.1007/s00432-008-0390-6

105. Giovannucci E, Harlan DM, Archer MC, Bergenstal RM, Gapstur SM, Habel LA, et al. Diabetes and cancer: a consensus report. Diabetes Care (2010) 33(7):1674-85. doi:10.2337/dc10-0666

106. Shikata K, Ninomiya T, Kiyohara Y. Diabetes mellitus and cancer risk: review of the epidemiological evidence. Cancer Sci (2010) 104(1):9-14. doi:10.1111/ cas. 12043

107. Peairs KS, Barone BB, Snyder CF, Yeh HC, Stein KB, Derr RL, et al. Diabetes mellitus and breast cancer outcomes: a systematic review and meta-analysis. J Clin Oncol (2010) 29(1):40-6. doi:10.1200/JCO.2009.27.3011

108. Xue F, Michels KB. Diabetes, metabolic syndrome, and breast cancer: a review of the current evidence. Am J Clin Nutr (2007) 86(3):s823-35.

109. Currie CJ, Poole CD, Jenkins-Jones S, Gale EA, Johnson JA, Morgan CL. Mortality after incident cancer in people with and without type 2 diabetes: impact of metformin on survival. Diabetes Care (2012) 35(2):299-304. doi: $10.2337 / \mathrm{dc} 11-1313$

110. Jiralerspong S, Kim ES, Dong W, Feng L, Hortobagyi GN, Giordano SH. Obesity, diabetes, and survival outcomes in a large cohort of early-stage breast cancer patients. Ann Oncol (2013) 24(10):2506-14. doi:10.1093/annonc/mdt224

111. Singh S, Singh PP, Singh AG, Murad MH, McWilliams RR, Chari ST. Antidiabetic medications and risk of pancreatic cancer in patients with diabetes mellitus: a systematic review and meta-analysis. Am J Gastroenterol (2013) 108(4):510-9. doi:10.1038/ajg.2013.7

112. Onitilo AA, Engel JM, Glurich I, Stankowski RV, Williams GM, Doi SA. Diabetes and cancer II: role of diabetes medications and influence of shared risk factors. Cancer Causes Control (2012) 23(7):991-1008. doi:10.1007/s10552012-9971-4

113. Kim YH, Ryu JM, Lee YJ, Han HJ. Fibronectin synthesis by high glucose level mediated proliferation of mouse embryonic stem cells: involvement of ANG II and TGF-beta1. J Cell Physiol (2010) 223(2):397-407. doi:10.1002/jcp.22048

114. Lin S, Sahai A, Chugh SS, Pan X, Wallner EI, Danesh FR, et al. High glucose stimulates synthesis of fibronectin via a novel protein kinase C, Raplb, and B-Raf signaling pathway. J Biol Chem (2002) 277(44):41725-35. doi:10.1074/ jbc.M203957200

115. Kolm-Litty V, Sauer U, Nerlich A, Lehmann R, Schleicher ED. High glucoseinduced transforming growth factor betal production is mediated by the hexosamine pathway in porcine glomerular mesangial cells. J Clin Invest (1998) 101(1):160-9. doi:10.1172/JCI119875

116. Rocco MV, Chen Y, Goldfarb S, Ziyadeh FN. Elevated glucose stimulates TGFbeta gene expression and bioactivity in proximal tubule. Kidney Int (1992) 41(1):107-14. doi:10.1038/ki.1992.14

117. Smoak IW. Hyperglycemia-induced TGFbeta and fibronectin expression in embryonic mouse heart. Dev Dyn (2004) 231(1):179-89. doi:10.1002/dvdy. 20123

118. Altschul SF, Madden TL, Schaffer AA, Zhang J, Zhang Z, Miller W, et al. Gapped BLAST and PSI-BLAST: a new generation of protein database search programs. Nucleic Acids Res (1997) 25(17):3389-402. doi:10.1093/nar/25.17.3389

119. Shaw JL, Diamandis EP. Distribution of 15 human kallikreins in tissues and biological fluids. Clin Chem (2007) 53(8):1423-32. doi:10.1373/clinchem.2007. 088104
120. Kryza T, Achard C, Parent C, Marchand-Adam S, Guillon-Munos A, Iochmann $\mathrm{S}$, et al. Angiogenesis stimulated by human kallikrein-related peptidase 12 acting via a platelet-derived growth factor B-dependent paracrine pathway. FASEB $J$ (2014) 28(2):740-51. doi:10.1096/fj.13-237503

121. Lu Z, Cui M, Zhao H, Wang T, Shen Y, Dong Q. Tissue kallikrein mediates neurite outgrowth through epidermal growth factor receptor and flotillin-2 pathway in vitro. Cell Signal (2014) 26(2):220-32. doi:10.1016/j.cellsig.2013. 10.010

122. Borgono CA, Diamandis EP. The emerging roles of human tissue kallikreins in cancer. Nat Rev Cancer (2004) 4(11):876-90. doi:10.1038/nrc1474

123. Batra J, O’Mara T, Patnala R, Lose F, Clements JA. Genetic polymorphisms in the human tissue kallikrein (KLK) locus and their implication in various malignant and non-malignant diseases. Biol Chem (2012) 393(12):1365-90. doi:10.1515/hsz-2012-0211

124. Kuzmanov U, Jiang N, Smith CR, Soosaipillai A, Diamandis EP. Differential $\mathrm{N}$-glycosylation of kallikrein 6 derived from ovarian cancer cells or the central nervous system. Mol Cell Proteomics (2009) 8(4):791-8. doi:10.1074/mcp. M800516-MCP200

125. Goletz S, Hanisch FG, Karsten U. Novel alphaGalNAc containing glycans on cytokeratins are recognized invitro by galectins with type II carbohydrate recognition domains. J Cell Sci (1997) 110(Pt 14):1585-96.

126. Chou CF, Smith AJ, Omary MB. Characterization and dynamics of Olinked glycosylation of human cytokeratin 8 and 18. J Biol Chem (1992) 267(6):3901-6.

127. Hatsell S, Medina L, Merola J, Haltiwanger R, Cowin P. Plakoglobin is Oglycosylated close to the N-terminal destruction box. J Biol Chem (2003) 278(39):37745-52. doi:10.1074/jbc.M301346200

128. Hu P, Berkowitz P, Madden VJ, Rubenstein DS. Stabilization of plakoglobin and enhanced keratinocyte cell-cell adhesion by intracellular O-glycosylation. J Biol Chem (2006) 281(18):12786-91. doi:10.1074/jbc.M511702200

129. Lommel M, Winterhalter PR, Willer T, Dahlhoff M, Schneider MR, Bartels MF, et al. Protein O-mannosylation is crucial for E-cadherin-mediated cell adhesion. Proc Natl Acad Sci U S A (2013) 110(52):21024-9. doi:10.1073/pnas. 1316753110

130. Ha JR, Hao L, Venkateswaran G, Huang YH, Garcia E, Persad S. $\beta$-Catenin is O-GlcNAc glycosylated at serine 23: implications for beta-catenin's subcellular localization and transactivator function. Exp Cell Res (2014) 321(2):153-66. doi:10.1016/j.yexcr.2013.11.021

Conflict of Interest Statement: The author declares that the research was conducted in the absence of any commercial or financial relationships that could be construed as a potential conflict of interest.

Received: 27 November 2013; accepted: 11 March 2014; published online: 25 March 2014.

Citation: Freire-de-Lima L (2014) Sweet and sour: the impact of differential glycosylation in cancer cells undergoing epithelial-mesenchymal transition. Front. Oncol. 4:59. doi: $10.3389 /$ fonc.2014.00059

This article was submitted to Molecular and Cellular Oncology, a section of the journal Frontiers in Oncology.

Copyright (C) 2014 Freire-de-Lima. This is an open-access article distributed under the terms of the Creative Commons Attribution License (CC BY). The use, distribution or reproduction in other forums is permitted, provided the original author(s) or licensor are credited and that the original publication in this journal is cited, in accordance with accepted academic practice. No use, distribution or reproduction is permitted which does not comply with these terms. 